\title{
Determination of thermal constant and development threshold of Bihar hairy caterpillar, Spilarctia obliqua Walker
}

\author{
K. Selvaraj*, B. S. Gotyal, V. Ramesh Babu and S. Satpathy \\ Division of Crop Protection, Central Research Institute for Jute and Allied Fibres, Barrackpore, Kolkata-700120, \\ INDIA \\ *Corresponding author. E-mail: selvaentomo@yahoo.co.in \\ Received: August 18, 2014; Revised received: October 01, 2014.; Accepted: November 13, 2014
}

\begin{abstract}
Effect of six constant temperatures viz., $18 \pm 1,21 \pm 1,24 \pm 1,27 \pm 1,30 \pm 1$ and $33 \pm 1^{\circ} \mathrm{C}$ was studied on the egg hatchability, larval pupal development and adult survival of Spilarctia obliqua. Development rate of egg, larva and pupa gradually increased with increase in temperature, while total developmental period decreased. Mean developmental period of the pest decreased from 93.73 days at $18 \pm 1^{\circ} \mathrm{C}$ to 31.20 at $33 \pm 1^{\circ} \mathrm{C}$. The lowest and the highest temperatures at which no development took place were found to be $12 \pm 1^{\circ} \mathrm{C}$ and $39 \pm 1^{\circ} \mathrm{C}$, respectively. Regression equations between development rate and temperature were found to be $Y=0.0189 X-0.1998\left(R^{2}=0.88\right)$ for egg, $Y=0.00122 X-0.0248\left(R^{2}=0.84\right)$ for small larva $\left(1-3^{\text {rd }}\right.$ instar $), Y=0.0058 X-0.0675\left(R^{2}=0.76\right)$ for large larva (4-6 ${ }^{\text {th }}$ instar), $Y=0.0074 X-0.1075\left(R^{2}=0.94\right)$ for pupa and $Y=0.0142 X-0.4363\left(R^{2}=0.79\right)$ for adults. Developmental threshold were determined to be $10.57,11.27,11.55,15.28$ and $10.92^{\circ} \mathrm{C}$ for egg, small larva, large larva, pupa, and adult respectively with corresponding thermal constant being 52.91, 344.82, 243.90, 142.85 and 70.42 degree days (DD). Thermal constant to complete a generation was found to be $854.90 \mathrm{DD}$. This was the first studies on this aspects, these estimated thermal thresholds and degree days could be used to predict the S. obliqua activity in the field for their effective management through pest forecasting.
\end{abstract}

Keywords: Constant temperature, Degree day, Spilarctia obliqua, Thermal constant, Threshold of development

\section{INTRODUCTION}

Spilarctia obliqua Walker (Lepidoptera: Arctiidae), known as jute hairy caterpillar (Bihar hairy caterpillar) is a highly polyphagous nature, it attacks pulses, oilseeds, cereals, certain vegetables, mulberry, medicinal, aromatic including bast fibre crops such as jute, mesta, ramie and sunnhemp and causes severe economic damage (Gupta and Bhattacharya, 2008) and has been reported from many countries of the world (Singh and Sehgal, 1992). In India, current area under these crops is $0.79 \mathrm{~m}$ ha with production $1.98 \mathrm{~m}$ tonnes of fibres during 2012-13 (IJSG, 2013). It is one of the major pests of bast fibre crops like jute (Corchorus spp.) and mesta (Hibiscus spp.) and cause a total foliage loss up to $20-75 \%$ in jute plantations in West Bengal, India. The pest infestation besides having direct adverse effect on yield also affect the quality of the fibres. The loss varies with the intensity of infestation, host plant quality and weather conditions. In recent years, outbreaks of this pest noticed during 2011 in jute and 2012 in sunnhemp crop and causing substantial loss to the fibre yield (Satpathy et al., 2013). The cultivation of high yieldingfertilizer responsive cultivars, gradual change in the cropping patterns in the jute and mesta growing areas and change in the climatic condition $S$. obliqua ISSN : 0974-9411 (Print), 2231-5209 (Online) All Rights Reserved ( A Applied and Natural Science Foundation www.ansfoundation.org assumed the major status (Satpathy et al., 2014). The female moths lay eggs in clusters on lower surface of the leaves and single female may lay up to 1000 eggs. Upon hatching, the young caterpillars (first to third instar) feed gregariously on the lower epidermis of the leaves and solitarily in the late (fourth to sixth instar) larval stages (Gupta and Bhattacharya, 2008). The whole leaf tissues are eaten up by the caterpillars, leaving only the ribs and the plants may be completely defoliated. Although the caterpillars prefer mature leaves, the top shoots are eaten up in case of severe attack. Timely management of this pest is very important as delay may even lead to complete defoliation of crop if remains unchecked in the field. For timely detection of this insect pest through development of temperature driven phenological model is pre-requite.

Among the climatic factors, temperature is the most important, as it has profound influence on the development and survival of insects (Trudgill et al., 2005). The rate of insect development is affected by the temperature to which insects are exposed. Insects require a certain amount of heat units (degree days) to develop from one life stage to the other (Bergant and Trdan, 2006). Thermal constant (K), expressed in degree-days (DD), is the amount of heat that each species requires to complete its lifecycle or part of it, 
regardless of the temperature to which it is exposed (Urra and Apablaza, 2005). Thermal constant provides better prediction of insect development than developmental period. Depending upon ambient temperature and development threshold, heat units are accumulated until fulfillment of thermal constant requirement, which heralds completion of development of insect life cycle or a development stage (Selvaraj et al., 2014). Quantification of the relationship between insect development and temperature is useful to predict the seasonal occurrence and population dynamics of the insects. The ability of an insect to develop at different temperatures is an important adaptation to survive under various climatic conditions. Further, understanding phenology of an insect species at different temperatures is crucial for predicting its seasonal occurrence and planning for integrated management. So far, there is no published report from India on the effect of constant temperatures on S. obliqua. Hence in the present study, developmental periods of different stages of $S$. obliqua were examined at six constant temperatures to estimate the temperature thresholds and thermal requirements, which would be useful in pest forecasting, monitoring, timing of insecticide applications (Zalom et al., 1983), analyzing distribution and abundance of insect populations (Demos and Sultani, 2012) and predicting consequence of global warming on population dynamics (Selvaraj et al., 2014). Keeping this in view, present study was undertaken to determine thermal constant and development threshold for development stages of Bihar hairy caterpillar (S. obliqua).

\section{MATERIALS AND METHODS}

Insect culture: The larvae of $S$. obliqua, collected from unsprayed crop at Central Research Institute for Jute and Allied Fibres (CRIJAF), Research Farm. Further, insect culture was maintained by providing jute leaves (Corcorus olitorius) as food in the rearing container $(13 \mathrm{~cm}$ height $\mathrm{x} 13 \mathrm{~cm}$ dia) with temperature $27 \pm 2^{\circ} \mathrm{C}$ and relative humidity $85 \%$. Progeny of laboratory reared $S$. obliqua was used in the experiments.

Temperature dependent development of $S$. obliqua, life stages: A freshly emerged female-male moths was released for oviposition on 40 days old jute plant in oviposition cages. After 24 hours after moth release, lower leaf surface containing eggs were transferred to test tubes. 30 eggs kept in each tubes with five replication, these tubes further placed in BODs at $9 \pm 1$, $12 \pm 1,15 \pm 1,18 \pm 1,21 \pm 1,24 \pm 1,27 \pm 1,30 \pm 1,33 \pm 1$, $36 \pm 1$ and $39 \pm 1{ }^{\circ} \mathrm{C}$ with $65-70 \% \mathrm{RH}$ and development of different stages of the pest was observed. However, the entire life cycle could be studied only at $18 \pm 1$, $21 \pm 1,24 \pm 1,27 \pm 1,30 \pm 1$ and $33 \pm 1^{\circ} \mathrm{C}$, whereas at $9 \pm 1$, $12 \pm 1,15 \pm 1,36 \pm 1$ and $39 \pm 1^{\circ} \mathrm{C}$ only egg hatchability was observed in order to determine the highest and lowest temperature limit for pest development. Observations on egg hatching, larval and pupal duration, and adult emergence were recorded at $24 \mathrm{~h}$ interval. Based on the data generated, the duration of incubation, small larvae (1-3 ${ }^{\text {rd }}$ instar), large larvae (4$6^{\text {th }}$ instar), pupae and adult survival were calculated at each of the temperatures.

Determination of thermal constant and development threshold of different $\boldsymbol{S}$. obliqua stages: Six larval instar of the $S$. obliqua were clubbed into two groups, first three into one and last three in another, hence forth called small larvae (SLV) and large larvae (LLV), respectively. Development rate for egg, SLV, LLV and pupal stage was calculated as reciprocal of their respective developmental duration (D) such that $\mathrm{R}=1 / \mathrm{D}$.

Development threshold and thermal constant were then determined by regressing development rate on temperature (Kipyatov and Lopatina, 2010). According to rule of the constant sum of effective temperatures:

$\left(\mathrm{T}-\mathrm{T}_{0}\right) \times \mathrm{D}=\mathrm{K}$

Where $\mathrm{T}$ - temperature at which insect species is reared, $\mathrm{T}_{0}$ - development threshold, D- duration of development and $\mathrm{K}$ - thermal constant

The $\mathrm{K}$ was estimated as reciprocal of regression coefficient (b) between development rate and temperature. $\mathrm{K}=1 / \mathrm{b}$

The $T_{o}$ was determined as ratio of regression intercept (a) and $b$

$\mathrm{T}_{0}=-\mathrm{a} / \mathrm{b}$

\section{RESULTS AND DISCUSSION}

Temperature dependent development of $S$. obliqua life stages: Temperature is the most important and critical abiotic factor exerting profound influence on the development of insects. The relationship between temperature and rate of development is crucial, as it influences insect biology, distribution, and abundance (Demos and Sultani, 2012; Padmavathi et al., 2013). During present study, the results revealed that the development rate of $S$. obliqua egg, larva and pupa gradually increased with increase in temperature, while total developmental period and adult survival period decreased. Temperature increase from $18 \pm 1^{\circ} \mathrm{C}$ to $33 \pm 1{ }^{\circ} \mathrm{C}$ reduced incubation period from 9.50 days to 2.00 days, while mean development duration of small larvae, large larvae, pupae and adult survival decreased from 32.33 to $14.00,25.18$ to $8.54,17.20$ to $4.66,9.52$ to 2.00 days, respectively with temperature increase from $18 \pm 1$ to $33 \pm 1{ }^{\circ} \mathrm{C}$ (Table 1). Total developmental duration of $S$. obliqua was 93.73, $76.37,64.35,45.08,38.91$ and 31.20 days at $18 \pm 1$, $21 \pm 1,24 \pm 1,27 \pm 1,30 \pm 1$ and $33 \pm 1^{\circ} \mathrm{C}$, respectively. Mean developmental period of the pest decreased from 93.73 days at $18 \pm 1^{\circ} \mathrm{C}$ to 31.20 days at $33 \pm 1{ }^{\circ} \mathrm{C}$. Although at $33 \pm 1{ }^{\circ} \mathrm{C}$, the eggs hatched and larvae converted to pupae but newly emerged moths were 
malformed. The lowest and the highest temperatures at which no development took place were found to be $15 \pm 1^{\circ} \mathrm{C}$ and $39 \pm 1^{\circ} \mathrm{C}$, respectively. At $15 \pm 1^{\circ} \mathrm{C}$ eggs did not hatch even after one month, while at $36 \pm 1^{\circ} \mathrm{C}$ eggs hatched but larvae did not survive and died immediately after hatching. Therefore, present study clear shows that from $18 \pm 1^{\circ} \mathrm{C}$ to $33 \pm 1^{\circ} \mathrm{C}$ development rate of $S$. obliqua was a linear function of temperature. Similar results were obtained by Padmavathi et al. (2013); Li et al. (2013); Selvaraj et al. (2014) on Cnaphalocrosis medinalis, Athetis lepigone and Sesamia inferens, respectively.

The results showed that the percent egg hatchability decreased with increasing temperature from $96.80 \%$ at $18 \pm 1^{\circ} \mathrm{C}$ to $79.20 \%$ at $33 \pm 1^{\circ} \mathrm{C}$ (Table 2) while percentage of larvae reaching to fourth instar in different temperature was at $96.50 \%$ at $18 \pm 1^{\circ} \mathrm{C}$ to $90.10 \%$ at $33 \pm 1{ }^{\circ} \mathrm{C}$ (Table 2). Likewise, percent pupation and adult emergence was found to be $97.70 \%$ at $18 \pm 1^{\circ} \mathrm{C}$ to $82.30 \%$ at $33 \pm 1^{\circ} \mathrm{C}$ and $97.30 \%$ at $18 \pm 1^{\circ} \mathrm{C}$ to $92.50 \%$ at $33 \pm 1{ }^{\circ} \mathrm{C}$, respectively. The overall survival of different stages of $S$. obliqua in different temperatures varied from $90.54 \%$ at $18 \pm 1{ }^{\circ} \mathrm{C}$ to $54.50 \%$ at $33 \pm 1{ }^{\circ} \mathrm{C}$. Temperature thus influenced incubation period more than it influenced egg hatchability, and pupation and adult emergence. Earlier studies on effect of constant temperature on $S$. obliqua revealed that larval period, larval survival, pupal periods, hatchability and incubation period decreased with increase in temperature from 25 to $30^{\circ} \mathrm{C}$. At $40^{\circ} \mathrm{C}$ there was no survival of larvae (Singh and Singh, 1993; Deshmukh et al., 1982).

Development threshold and thermal constant for $\boldsymbol{S}$. obliqua: Information on temperature-dependent duration was used to determine the threshold of development and threshold constant for different $S$. obliqua developmental stages. The regression equations were established between temperatures and respective developmental rate which was reciprocal of duration of development of stages. The thermal constant and threshold temperature for different stages of S. obliqua was determined through this regression equation. Regression equations between development rate and temperature were found to be $\mathrm{Y}=0.0189 \mathrm{X}$ $0.1998 \quad\left(\mathrm{R}^{2}=0.88\right)$ for egg, $\mathrm{Y}=0.00122 \mathrm{X}-0.0248$ $\left(\mathrm{R}^{2}=0.83\right)$ for small larva, $\mathrm{Y}=0.0058 \mathrm{X}-0.0675$ $\left(\mathrm{R}^{2}=0.76\right)$ for large larva, $\mathrm{Y}=0.0074 \mathrm{X}-0.1075$ $\left(\mathrm{R}^{2}=0.94\right)$ for pupa and $\mathrm{Y}=0.0142 \mathrm{X}-0.4363\left(\mathrm{R}^{2}=0.79\right)$

Table 1. Effect of temperature on development of different stages of S. obliqua.

\begin{tabular}{|c|c|c|c|c|c|c|}
\hline \multirow{2}{*}{$\begin{array}{l}\text { Temperature } \\
\left({ }^{\circ} \mathrm{c}\right)\end{array}$} & \multicolumn{5}{|c|}{ Duration of different stages of $S$. obliqua (Days \pm SD) } & \multirow{2}{*}{$\begin{array}{c}\text { Total } \\
\text { developmental } \\
\text { period (days) }\end{array}$} \\
\hline & $\begin{array}{c}\text { Egg } \\
\text { incubation } \\
\text { period }\end{array}$ & $\begin{array}{l}\text { Small lar- } \\
\text { vae (upto } \\
3^{\text {rd }} \text { instar) }\end{array}$ & $\begin{array}{c}\text { Large larvae } \\
\text { (From 4th } \\
\text { and above) }\end{array}$ & Pupae & Adult & \\
\hline $18 \pm 1$ & $9.5 \pm 0.50$ & $32.33 \pm 0.66$ & $25.18 \pm 0.26$ & $17.20 \pm 0.39$ & $9.52 \pm 0.50$ & 93.73 \\
\hline $21 \pm 1$ & $7.5 \pm 0.50$ & $26.16 \pm 0.50$ & $20.11 \pm 0.26$ & $15.40 \pm 0.26$ & $7.20 \pm 0.50$ & 76.37 \\
\hline $24 \pm 1$ & $5.5 \pm 0 . .50$ & $23.60 \pm 0.50$ & $16.30 \pm 0.70$ & $13.2 \pm 0.26$ & $5.75 \pm 0.50$ & 64.35 \\
\hline $27 \pm 1$ & $4.5 \pm 0.50$ & $18.33 \pm 0.57$ & $10.20 \pm 0.29$ & $7.75 \pm 0.39$ & $4.30 \pm 0.50$ & 45.08 \\
\hline $30 \pm 1$ & $3.0 \pm 0.00$ & $17.00 \pm 1.00$ & $9.60 \pm 0.32$ & $6.75 \pm 0.47$ & $2.56 \pm 0.50$ & 38.91 \\
\hline $33 \pm 1$ & $2.0 \pm 0.00$ & $14.00 \pm 1.00$ & $8.54 \pm 0.51$ & $4.66 \pm 0.30$ & $2.00 \pm 0.00$ & 31.20 \\
\hline
\end{tabular}

Mean \pm SD of five values

Table 2. Effect of temperature on survival of $S$. obliqua under laboratory conditions.

\begin{tabular}{lccccc}
\hline $\begin{array}{l}\text { Temperature } \\
\left({ }^{\circ} \mathrm{C}\right)\end{array}$ & $\begin{array}{c}\text { Egg } \\
\text { hatchability } \\
(\%)\end{array}$ & $\begin{array}{c}\text { Larvae reaching } \\
\text { fourth instar } \\
(\%)\end{array}$ & $\begin{array}{c}\text { Total } \\
\text { pupation } \\
(\mathbf{\%})\end{array}$ & $\begin{array}{c}\text { Adult } \\
\text { emergence } \\
(\%)\end{array}$ & $\begin{array}{c}\text { Overall } \\
\text { development } \\
(\%)\end{array}$ \\
\hline $18 \pm 1$ & 96.80 & 96.50 & 97.70 & 97.30 & 90.54 \\
$21 \pm 1$ & 95.70 & 96.20 & 95.30 & 96.40 & 81.92 \\
$24 \pm 1$ & 95.30 & 95.30 & 94.00 & 95.80 & 78.65 \\
$27 \pm 1$ & 93.30 & 93.70 & 92.10 & 95.70 & 68.12 \\
$30 \pm 1$ & 85.00 & 92.20 & 84.20 & 94.30 & 64.25 \\
$33 \pm 1$ & 79.20 & 90.10 & 82.30 & 92.50 & 54.50 \\
\hline
\end{tabular}

Table 3. Determination of threshold temperatures and thermal constant for different developmental stages of S. obliqua.

\begin{tabular}{|c|c|c|c|c|}
\hline $\begin{array}{l}\text { Developmental } \\
\text { stage }\end{array}$ & Regression equation & $\begin{array}{l}\text { Thermal constant }(K) \\
(K=1 / b)\end{array}$ & $\begin{array}{l}\text { Temperature threshold } \\
\left(T_{0}\right)\left(T_{0}=a / b\right)\end{array}$ & $\mathbf{R}^{2}$ \\
\hline Egg & $\mathrm{Y}=0.0189 \mathrm{X}-0.1998$ & 52.91 & 10.57 & 0.88 \\
\hline Small larva & $Y=0.0122 X-0.0248$ & 344.82 & 11.27 & 0.84 \\
\hline Large larva & $Y=0.0058 X-0.0675$ & 243.90 & 11.55 & 0.76 \\
\hline Pupa & $Y=0.0074 X-0.1075$ & 142.85 & 15.28 & 0.94 \\
\hline Adult & $Y=0.0142 X-0.4363$ & 70.42 & 10.92 & 0.79 \\
\hline
\end{tabular}




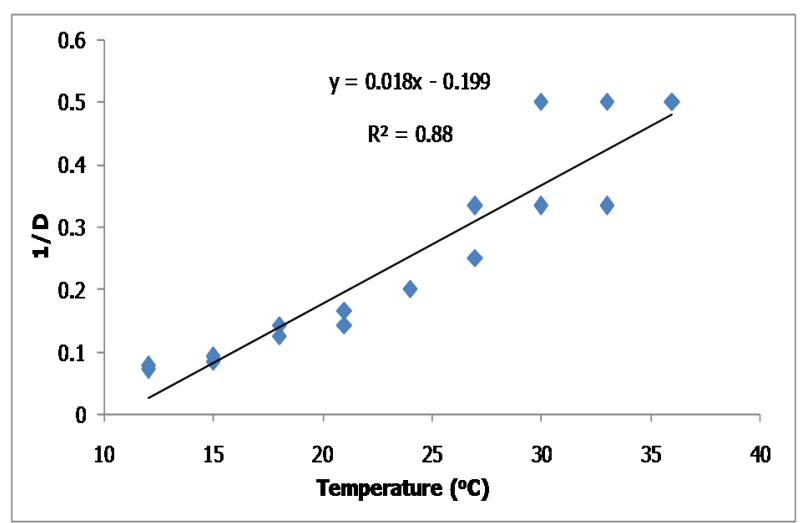

Fig.1. Regression between temperature and mean incubation period of eggs of S. obliqua.

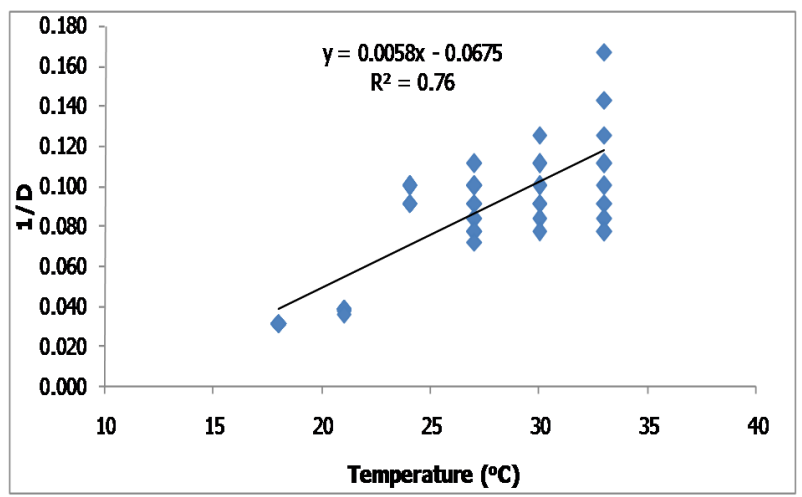

Fig. 3. Regression between temperature and mean development duration of large larvae (above $3^{\text {rd }}$ instar) of S. obliqua.

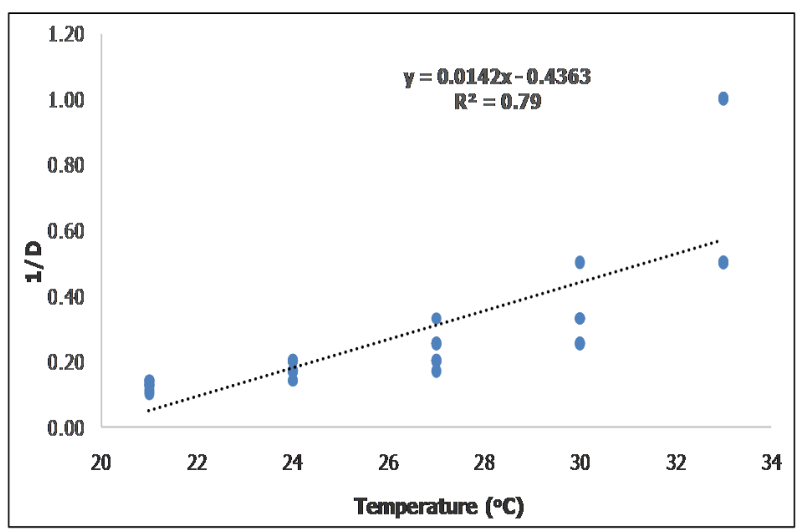

Fig. 5. Regression between temperature and mean development duration of adult of S. obliqua.

for adults (Table 3; Figs. 1-5). Developmental threshold were determined to be 10.57, 11.27, 11.55, 15.28 and $10.92^{\circ} \mathrm{C}$ for egg, small larva, large larva, pupa, and adult respectively with corresponding thermal constant being 52.91, 344.82, 243.90, 142.85 and 70.42 degree days (DD). Above development threshold, development rate increase proportionally to temperature rise until upper threshold. At the upper limit the rate decreases rapidly to zero (Briere et al., 1999). Even though insects are not always subject to constant temperatures in nature; a controlled study can provide a valuable insight into the population

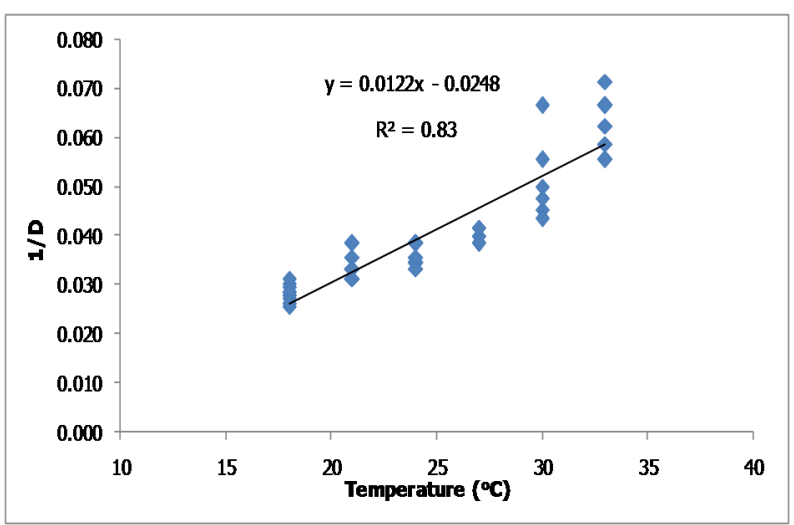

Fig.2. Regression between temperature and mean development duration of small larvae (1-3 instar) of S. obliqua.

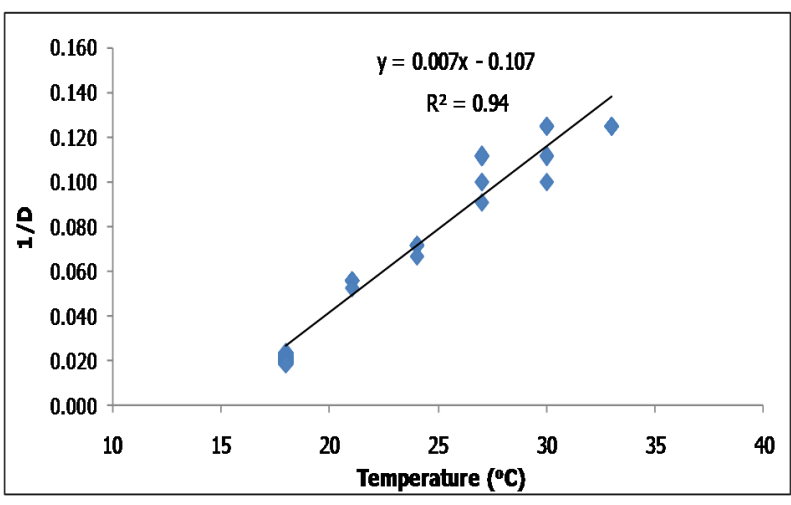

Fig. 4. Regression between temperature and mean development duration of pupae of S. obliqua.

dynamics of a particular species (Summers et al., 1984). Thermal constant provides better prediction of insect development than developmental period. Depending upon ambient temperature and development threshold, heat units are accumulated until fulfillment of thermal constant requirement, which heralds completion of development of insect life cycle or a development stage. Besides, temperature also affected the $S$. obliqua population through its affect on survival of different developmental stages. The regression between development rate of various developmental stages and temperature was undertaken and this was used to estimate thermal constant and development threshold unlike other methods (Kipyatov and Lopatina, 2010). This method provided single value of thermal constant and development threshold for various development stages of S. obliqua where pairs of temperature and corresponding development period often yielded different values of development threshold and finally that of thermal constant for the same developmental stage of an insect.

\section{Conclusion}

In this study, we found various characteristics of the temperature response of the $S$. obliqua and the effective temperature requirements for different developmental stages. Results show that development rate of various life stages increases with the 
temperature from $18 \pm 1^{\circ} \mathrm{C}$ to $33 \pm 1^{\circ} \mathrm{C}$ for $S$. obliqua. This thermal information helpful to develop phenology model based on DD which can be useful for integrated pest management (IPM) decision making and pest dynamics under changing climatic scenarios. The thermal constant provides a valuable tool for insect pest control; in forecasting infestations monitoring, to predict the appearance of insect stages and timing of insecticide application in order to control them in a timely manner, ensuring its rational management. Besides, the thermal constant can be used as indicators of the distribution and abundance of insect populations. The validation of this temperature threshold and thermal constant is the next step to develop a forecasting model for predicting the occurrence of S. obliqua under field conditions.

\section{ACKNOWLEDGEMENT}

We acknowledge the Director, CRIJAF as well as Head, Crop Protection Division for providing for providing facilities to conduct this experiment.

\section{REFERENCES}

Bergant, K and Trdan, S. (2006). How reliable are thermal constants for insect development when estimated from laboratory experiments?. Entomologia Experimentalis et Applicata, 120: 251-256.

Briere, J.F., Pracros, P., Roux, A.P and Pierre, J.S. (1999). A novel model of temperature-dependent development for arthropods. Environmental Entomology, 28:22-29.

Damos, P and Soultani, M.S. (2012). Temperature-driven models for insect development and vital thermal requirements. Psyche, doi:10.1155/2012/123405.

Deshmukh, P.D., Rathore, Y.S. and Bhattacharya, A.K. (1982). Effect of temperature on the growth and development of Diacrisia obliqua Walker on five host plants. Indian Journal of Entomology, 44(1): 21 -33.

Gupta, G. and Bhattacharya, A.K (2008) Assessing toxicity of post-emergence herbicides to the Spilarctia obliqua Walker (Lepidoptera: Arctiidae). Journal of Pest Science, 81 (1): 9-15.

IJSG. (2013). International Jute Study group (IJSG). Annual report 2012-13. pp 181.

Kipyatkov, V.E and Lopatina, E.B. (2010). Intra-specific variation of thermal reaction norms for development in insects: new approaches and prospects. Entomological Review, 90 (2): 163-184.

Li, L.T., Wang, Y.Q., Ma, J.F., Liu, L., Hao, Y.T., Dong, C., Gan, Y.J., Dong, Z.P., Wang, Q.Y. (2013). The effects of temperature on the development of the moth Athetis lepigone, and a prediction of field occurrence. Journal of Insect Science 13 : (103)1-13.

Padmavathi, C., Katti, G., Sailaja, V., Padmakumari, A.P., Jhansilakshmi, V., Prabhakar, M. and Prasad, Y.G. (2013). Temperature thresholds and thermal requirements for the development of the rice leaf folder, Cnaphalocrocis medinalis. Journal of Insect Science, 16 (96):1-14.

Satpathy, S., Biswas, C., Sarkar, S.K., Selvaraj, K and Gotyal, B.S., De, R.K., Gawande, S.P., Ramesh Babu, V., Tripathi, A.N and Tripathi, M.K. (2013). Changing pest and disease status and prospects of pest management in jute and allied fibre crops. Presented in national seminar on Jute and allied fibres in changing times: issues and Strategies on 3-5 January, 2013, Kolkata .52p.

Satpathy, S., Selvaraj, K., Gotyal, B.S., Biswas, C., Gawande, S.P., Sarkar, S.K., De, R.K., Tripathi, A.N., Ramesh Babu, V., Mondal, K. and Meena, P.N. (2014). Problems and prospects of pest management in jute and allied fibre crops. Presented in "International Conference on Natural Fibres (Jute and Allied Fibres) on 13 August, 2014, Kolkata.P 30-36.

Selvaraj, K., Chander, S. and Prasannakumar, N.R. (2014). Determination of thermal constant and development threshold of pink borer, Sesamia inferens Walker. The Proceedings of the National Academy of Sciences: Biological Sciences, DOI 10.1007/s40011-014-0348-1

Singh, G. and Singh, I. (1993). Comparative development and survival of Bihar hairy caterpillar (Spilosoma obliqua) at different temperature and on different varieties of sunflower at Ludhiana. Indian Journal of Agricultural Sciences, 63, 447-450.

Singh, S. and Sehgal, S.S. (1992). Studies on growth and development of Spilosoma obliqua Walker on different food plants. Indian Journal of Entomology, 54, 471482.

Summers, C.G., Coviello, R.L and Gutierrez, A.P. (1984). Influence of constant temperatures on the development and reproduction of Acyrthosiphon kondoi (Homoptera: Aphididae). Environmental Entomology, 13:236-242.

Trudgill, D.L., Honek, L.D. and Van Straalen, N.M. (2005). Thermal time-concepts and utility. Annals of Applied Biology, 146:1-14.

Urra, F and Apablaza, J. (2005). Threshold temperature and thermal constant for the development of Copitarsia decolora (Lepidoptera: Noctuidae). Ciencia e Investigación Agraria, 32(1): 16-23

Zalom, F.P., Goodell, L., Wilson, W. and Bentley, W. (1983). Degree days: the calculation and use of heat in pest management. Division of agricultural and natural resources, University of California, Davis, CA. USA.10 p. 